\title{
Research on the Dynamics Game Model in a Green Supply Chain: Government Subsidy Strategies under the Retailer's Selling Effort Level
}

\author{
Xigang Yuan $\left(\mathbb{D},{ }^{1,2}\right.$ Xiaoqing Zhang ${ }^{D},{ }^{1}$ and Dalin Zhang $^{3}$ \\ ${ }^{1}$ Business School, Jiangsu Normal University, Xuzhou 221116, China \\ ${ }^{2}$ School of Economics and Management, Southwest Jiaotong University, Chengdu 610031, China \\ ${ }^{3}$ School of Computing Science and Engineering, University of New South Wales, Sydney 2052, Australia
}

Correspondence should be addressed to Xiaoqing Zhang; xqzhang22@163.com

Received 1 February 2020; Accepted 27 May 2020; Published 16 June 2020

Academic Editor: Dimitri Volchenkov

Copyright (c) 2020 Xigang Yuan et al. This is an open access article distributed under the Creative Commons Attribution License, which permits unrestricted use, distribution, and reproduction in any medium, provided the original work is properly cited.

Based on dynamic game theory and the principal-agent theory, this paper examined different government subsidy strategies in green supply chain management. Assuming that the retailer's level of selling effort involved asymmetric information, this study analyzed the impact of different government subsidy strategies on the wholesale price, the product greenness level, retail price, the level of selling effort, the manufacturer's profit, and the retailer's profit. The results showed that (1) the government's subsidy strategy can effectively not only improve the product greenness level but also increase the profits of an enterprise in a green supply chain, which helps the retailer to enhance their selling effort; (2) regardless of whether the retailer's level of selling effort was high or low, as the government's subsidy coefficient increased, the wholesale price continued to decrease, and the product greenness level and retailer's selling effort level also increased.

\section{Introduction}

With the rapid development of the economy and society, living standards are improving and there is a trend of rapid growth with respect to energy consumption, all of which have led to intense pressure to control the emissions of harmful gases and reduce the impact of the greenhouse effect and cub environmental harm [1]. Thus, the development of the green economy and the control of greenhouse gas emissions have gradually become a hot topic. Green development and the environmental protection have become indispensable factors to measure healthy economic and societal development. Green supply chain management (GSCM) has also become a key point in academic research [2]. GSCM aims to enhance a firm's profit and maintain ecological efficiency at each stage of the product life cycle [3]. GSCM can enable firms to realize their coordination and development efforts. The integration of a green supply chain encourages enterprises to share information and cooperate with each other. The relationship between the supply chain and the environment means that
GSCM represents an inevitable trend in the area of sustainable economic development.

More and more enterprises have focused on GSCM and have implemented it in practice. As a result, enterprises pay greater attention to environmental protection and seek to reduce environmental pollution. For example, in terms of sustainable development, Lenovo explored the construction and implementation of GSCM, and the company strives to develop leading environmental products so as to minimize the impact on environment. Huawei has begun to work on GSCM and integrate the green concept into their entire procurement and production process. Apple Inc. encourages suppliers to participate in GSCM, implements energy transformation, and uses recycled or renewable materials as much as possible. Wal-Mart announced that, in the near future, the company will utilize only renewable energy sources, employ a zero waste strategy, and sell products that satisfy environmental standards.

However, as more and more enterprises participate in GSCM activities, they must also incur higher costs. 
Therefore, it is far from enough to rely on enterprises to promote GSCM practice, and the government should offer substantially more subsidies to firms that implement the GSCM model. The environmental laws and regulations that have been introduced by the government have encouraged enterprises to attach greater importance to GSCM activities. For example, "The directive restricting the use of hazardous substances in electrical and electronic equipment" was implemented in the European Union in 2006, while "The energy-saving products for the benefit of people" was carried out in China in 2009. It provided financial subsidies for ten categories of high-efficiency energy-saving products which have an energy efficiency grade one or above, and it is advantageous as it promotes the development of energysaving products. It is evident that the government plays a very important role in GSCM activity. On the one hand, the government can either reward or penalize the manufacturer with respect to their carbon emissions from their production processes, and this reward-penalty mechanism can be used to reduce carbon emissions. On the other hand, in order to improve the sale of green products, the government can subsidize retailers based on their selling effort. Thus, the impact of different types of government subsidy strategies on the green supply chain management should be worthy of considering.

The mainly purpose of this study is to discuss the impact of different types of government subsidy strategies on the green supply chain management. Thus, we consider a twolevel green supply chain system with one manufacturer and one retailer. Assuming that the retailer's level of selling effort involves asymmetric information, we examined the impact of different government subsidy strategies on their decisionmaking behavior by using dynamic game theory. The objectives of this paper include the following: (1) to explore how the different government subsidy strategies influence enterprise decision-making behavior and (2) to identify which types of government subsidy strategies are more effective for implementing GSCM.

The main contributions of this paper are as follows: (1) we build three dynamic game models, i.e., a game model without a government subsidy strategy (NG model), a game model with a government subsidized manufacturer (MG model), and a game model with a government subsidized retailer (RG model) in GSCM. Moreover, the retailer's level of selling effort is represented by asymmetric information. (2) We discuss the impact of different government subsidy strategies on decision-making behavior by using dynamic game theory. Moreover, we aimed to explore how different government subsidy strategies influence enterprise decision-making behavior. (3) We identify which types of government subsidy strategies are more effective for implementing GSCM.

The remainder of this paper was organized as follows: Section 2 reviews the relevant literature; the problem description and model assumptions are provided in Section 3; Section 4 presents the dynamics game model which was developed to analyze the impact of different government subsidy strategies on decision-making behavior; the simulation analysis and management implications are outlined in Section 5; and Section 6 presents the conclusions.

\section{Literature Review}

The government subsidy strategy has been thoroughly studied in the context of GSCM. The literature related to government subsidy strategies and the application of dynamic game theory in SCM and GSCM is reviewed and analyzed in this section. GSCM refers to the process of considering environmental problems at each link in the supply chain, and an emphasis is placed on environmental protection while promoting the coordinated development of the economy and the environment.

2.1. Government Subsidy Strategy in SCM and GSCM. The government plays a very important role in SCM and in GSCM. The government can implement a reward-penalty mechanism or subsidy strategy in order to reduce the cost of producing green products and improve the product greenness level. Runkel [4] analyzed the impact of government subsidy policies on GSCM. Subsequently, Aksen et al. [5] and Sheu [6] expanded the scope of research in this area by examining the influence of government policy on GSCM. Aksen et al. [5] studied the different impacts of the government's supportive policy and legislative policy on GSCM. Sheu [6] pointed out that the government's green legislation and the financial intervention policy could achieve the enterprise's interest coordination mechanism of GSCM. Ma et al. [7] studied how the consumption-subsidy strategy impacts dual channel GSCM. Benjaafar et al. [8] used low-carbon factors to solve operational management problems in GSCM. Toptal et al. [9] discussed the carbon emission reduction investment strategy problem in GSCM. Chen et al. [10] analyzed the retailer's optimal decision with green technology investment in GSCM. Chen et al. [11] developed an evolutionary game theory model of the interaction between governments and manufacturers based on static carbon taxes and subsidies. The results showed that the static carbon tax and subsidy mechanism implemented by the governments could not provide the needed positive impact on manufacturers decision-making. Kang et al. [12] examined supply chain operations when the supply chain participants acted individually and cooperatively in a "green poverty alleviation" supply chain in which the manufacturer initiated product "greening" and provided microfinance to alleviate the poverty of poor raw material suppliers by using dynamics game model. He et al. [13] considered a dualchannel closed-loop supply chain (CLSC) where a manufacturer could distribute new products through an independent retailer and sell remanufactured products via a third-party firm or platform (3P) in the presence of possible government subsidy. They found that government could encourage the manufacturer to adopt desired channel structures by setting appropriate subsidy levels.

Some scholars concentrated on the coordination problem under different government strategies. Huang et al. [14] discussed the government's subsidy strategy and highlighted how customers' bargaining power can influence customer' welfare. Zakeri et al. [15] analyzed the effect of carbon emission policies on operational management in the case of 
GSCM. Li et al. [16] studied the relationship between the manufacturer and retailer within the context of government carbon regulations, and the results showed that the investment cost contract can reduce carbon emissions in GSCM. Li et al. [17] analyzed the impact of government subsidy strategies on welfare by employing Nash game theory. $\mathrm{Li}$ and $\mathrm{Hu}$ [18] developed the Stackelberg game model, which considered the government reward-penalty mechanism, and analyzed the optimal solution under different situations. Zhang et al. [19] established four game models under fairness preferences in GSCM and compared the impact of parameters on the decision-making process. Gharaei et al. [20] proposed a green supply chain game model under a reward-penalty mechanism and green investment policy.

The above literature discussed the impact of different government strategies on GSCM. However, fewer scholars discuss this problem within the context of asymmetric information. In contrast to previous studies, this paper examined the effect of government subsidy strategies on the decision-making process in GSCM under the situation of asymmetric information.

2.2. Application of Dynamic Game Theory in SCM and GSCM. Dynamic game theory proposes that the actions of the players are in sequence, and that the latter can observe the choice of the former and make corresponding choices. Dynamic game theory has become a very important method that can be employed in theoretical and applied research. Many scholars discuss human economic decision-making behavior and solve operational management problems [21].

Although an extensive amount of research has studied many problems in different fields, few papers have examined the impact of government subsidy strategies on GSCM by using dynamic game theory. Wang et al. [22] developed a GSCM model with a dual collection channel without the government's reward-penalty mechanism and compared it with the government's reward-penalty mechanism. Su et al. [23] considered the impact of the environmental protection input on the whole green supply chain and analyzed the effect of centralized decision-making and decentralized decision-making on the returns and pricing strategies of each participant by using dynamic game theory. Sun et al. [24] studied green investment strategies under a government subsidy policy in a two-echelon green supply chain by employing dynamic game theory. He et al. [25] considered an online-to-offline (O2O) tourism supply chain (TSC) consisting of an offline tourism service provider (TSP) and an online travel agency (OTA) who has a corporate social responsibility (CSR). They built three game-theoretic models to explore the optimal online selling model and pricing decisions for the TSC and its members. The result showed that the TSC should pay more attention to CSR and improve consumers' channel acceptance for the reselling channel to create more total utility. Chen et al. [26] introduced the concept of equity as the incentive mechanism to coordinate the GSCM and established a new network equilibrium model using dynamic game theory. Zhang et al. [27] built three closed-loop supply chain dynamic game models using dynamics game theory and principal-agent theory. Moreover, they discussed the impact of government's rewardpenalty mechanism on the decision variables. He et al. [28] investigated a service supply chain (SC) consisting of a service provider (SP) who was in charge of carbon emission reduction and service, and a service integrator (SI) who was responsible for low-carbon advertising, considering corporate social responsibility (CSR). They found that consumers' low-carbon preference and chain members' marginal profits and CSR behaviors significantly influence the optimal solutions.

Based on the above analysis, large numbers of studies have considered governmental strategies in their research on GSCM. However, the aforementioned studies simply assumed that the information between all enterprises is symmetric. On the contrary, this paper considered a twolevel green supply chain system with one manufacturer and one retailer, and the retailer's level of selling effort is represented by asymmetric information. We build three dynamic game models, i.e., a game model without a government subsidy strategy (NG model), a game model with a government subsidized manufacturer (MG model), and a game model with a government subsidized retailer (RG model) in GSCM. We discuss the impact of different government subsidy strategies on decision-making behavior by using dynamic game theory. Moreover, we aimed to explore how different government subsidy strategies influence enterprise decision-making behavior. The results showed that government's subsidy strategy effectively improves not only the product greenness level but also the profits of an enterprise in GSCM, which helps the retailer to improve their own selling effort level.

\section{Problem Description and Model Assumptions}

3.1. Problem Description. In this section, we consider a twolevel green supply chain system with one manufacturer and one retailer (as shown in Figure 1). The manufacturer (as leader) sells green products to the retailer at the wholesale price $w$, and the retailer (as follower) sells green products to the consumer at price $p$. Assume that the level of selling effort represents asymmetric information. Furthermore, the retailer's selling cost not only corresponds to their own level of selling effort but also relates to the greenness level, and it can be expressed as $c_{r}=e^{2} g$. To simplify the analysis, the selling cost is divided into two types: $H$-type and $L$-type. While the manufacturer does not know the real information about the retailer's selling cost, it knows the probability distribution as $p\left(e_{H}\right)=v$ and $p\left(e_{L}\right)=1-v$. In order to identify the retailer's true information about the selling cost, the manufacturer can design a screening contract, thus permitting the retailer to make a rational choice by using the information screening method. The government can formulate different subsidy strategies for the manufacturer and the retailer. Therefore, the government can incentivize the manufacturer to produce green products while also encouraging the retailer to improve their selling effort. 


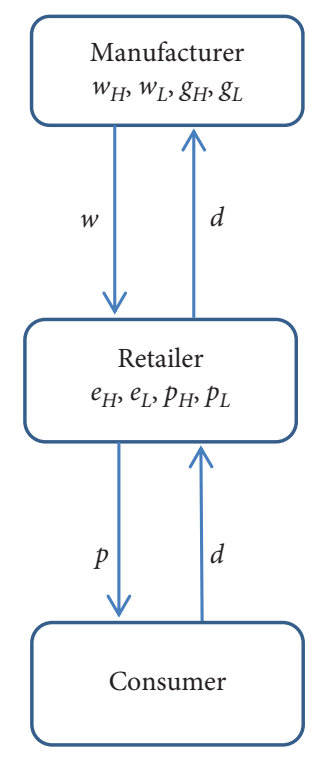

(a) NG model

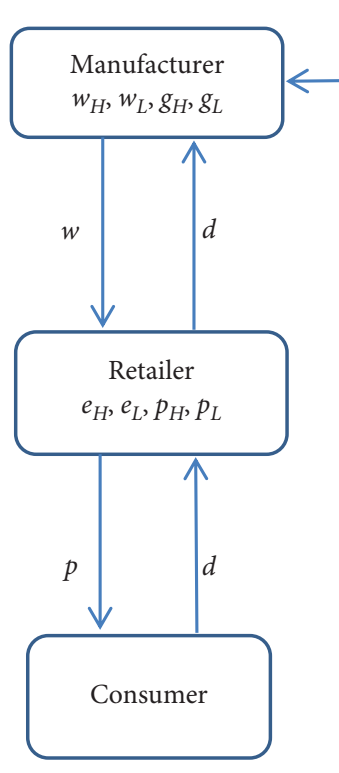

(b) $M G$ model

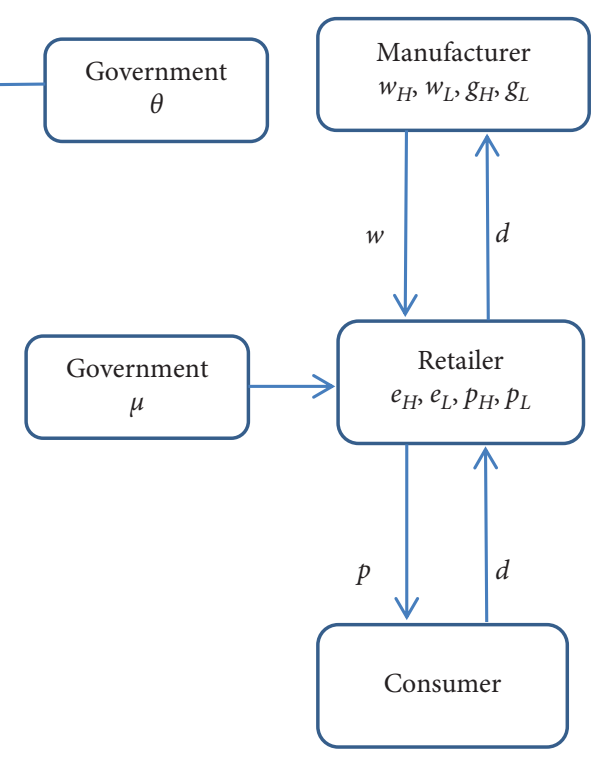

(c) $R G$ model

FIGURE 1: The theoretical model of the green supply chain considering government's subsidy strategy under asymmetric information.

The following symbols are used in the paper:

$c_{m}$ : the manufacturer's production cost

$w_{i}$ : the manufacturer's wholesale price which is the decision variable, $i \in\{H, L\}$, where $w_{H}$ expresses the high wholesale price and $w_{L}$ expresses the low wholesale price

$d$ : consumer's demand for green products from retailer $a$ : potential demand in consumer market, where $a>0$ $b$ : the sensitivity of market demand to price, where $b>0$ $p_{i}$ : the retailer's selling price which is the decision variable, $i \in\{H, L\}$, where $p_{H}$ expresses the high selling price and $p_{L}$ expresses the low selling price

$\lambda$ : consumer preference for green products

$g_{i}$ : product greenness level which is the decision variable, $i \in\{H, L\}$, where $g_{H}$ expresses a high greenness level and $g_{L}$ expresses a low greenness level (Ghosh and Shah $[29,30]$, Yang and Xiao [31], and Zhu and Dou [32])

$c_{r_{i}}$ : the retailer's selling cost, $i \in\{H, L\}$, where $c_{r_{H}}$ expresses a high selling cost and $c_{r L}$ expresses a low selling cost $e_{i}$ : the retailer's selling effort, $i \in\{H, L\}$, where $e_{H}$ expresses a high selling effort and $e_{L}$ expresses a selling effort $\theta$ : the coefficient of the unit product subsidy received by the manufacturer

$\mu$ : the coefficient of selling cost subsidy received by the retailer

$z$ : manufacturer's research and develop impact factor

3.2. Model Assumption. To formulate the problem, several assumptions were made:

(1) The manufacturer and the retailer are participants in the Stackelberg game, whereby the manufacturer is the leader and the retailer is the follower, and they can achieve optimal equilibrium by using dynamic game theory.

(2) Both the manufacturer and the retailer are risk neutral, and they pursue the maximization of their own interests.

(3) The retailer's level of selling effort is expressed as $e_{i}$, $i \in\{H, L\}, e_{L}<e_{H}$, which indicates that the retailer's high level of selling effort is higher than the retailer's low level of selling effort.

(4) To improve the greenness level, the government subsidizes the manufacturer. According to Yang and Xiao [31], Li et al. [33]; Yan et al. [34], and Zhang et al. [35], $\theta_{g}$ expresses the unit product subsidy received by the manufacturer.

(5) The government subsidizes the retailer on the basis of the selling cost, and $\mu e^{2} g$ expresses the total amount of subsidies received by the retailer.

(6) The manufacturer's production capacity is infinite, and it can meet the market demand.

\section{Dynamics Game Model in GSCM}

In the paper, the retailer's level of selling effort, which represents asymmetric information, can form a principleagent relationship between the manufacturer and the retailer. Information discrimination theory can be used to identify the type of the retailer's true selling cost. In addition, the contract design, which is expressed as $\left\{\left(e_{H}, w_{L}\right)\right.$, $\left.\left(e_{L}, w_{H}\right)\right\},\left\{\left(e_{H}, w_{L}\right)\right\}$, indicates that the high level of the retailer's selling effort prompts the manufacturer to offer a low wholesale price to the retailer. $\left\{\left(e_{L}, w_{H}\right)\right\}$ indicates that the low level of the retailer's selling effort prompts the manufacturer to offer a high wholesale price to the retailer. The government subsidy strategy was introduced into the game model. The government can implement a subsidy 
strategy for the manufacturer or retailer. We also carried out a comparative analysis with the nongovernment subsidy strategy.

4.1. GSCM Game Model without Government Subsidy Strategy (NG Model). This game model does not consider the government subsidy strategy, and the manufacturer and the retailer pursue the maximization of their own interests. As the entrusting party, the manufacturer identifies the type of the retailer's true selling cost and the contract design as $\left\{\left(e_{H}, w_{L}\right),\left(e_{L}, w_{H}\right)\right\}$. The game model is constructed as follows:

When the retailer's selling cost is high, its profit function can be expressed as

$$
\max _{p_{H}, e_{H}} \pi_{R_{H}}^{N G}=\left(p_{H}-\omega_{L}\right)\left(a-b p_{H}+\lambda g_{H}+e_{H}\right)-e_{H}^{2} g_{H} .
$$

When the retailer's selling cost is low, its profit function can be expressed as

$$
\max _{p_{L}, e_{L}} \pi_{R_{L}}^{N G}=\left(p_{L}-\omega_{H}\right)\left(a-b p_{L}+\lambda g_{L}+e_{L}\right)-e_{L}^{2} g_{L} .
$$

The manufacturer's profit function can be expressed as

$$
\begin{aligned}
\max _{g_{H}, g_{L}, \omega_{H}, \omega_{L}} \pi_{M}^{N G}= & v\left\{\omega_{L}\left(a-b p_{H}+\lambda g_{H}+e_{H}\right)-z g_{H}^{2}\right\} \\
& +(1-v)\left\{\omega_{H}\left(a-b p_{L}+\lambda g_{L}+e_{L}\right)-z g_{L}^{2}\right\} .
\end{aligned}
$$

The constraints can be expressed as

$$
\begin{aligned}
& \left(p_{H}-\omega_{L}\right)\left(a-b p_{H}+\lambda g_{H}+e_{H}\right)-e_{H}^{2} g_{H} \geq \pi_{0}, \\
& \left(p_{L}-\omega_{H}\right)\left(a-b p_{L}+\lambda g_{L}+e_{L}\right)-e_{L}^{2} g_{L} \geq \pi_{0}, \\
& \left(p_{H}-\omega_{L}\right)\left(a-b p_{H}+\lambda g_{H}+e_{H}\right)-e_{H}^{2} g_{H} \geq\left(p_{L}-\omega_{H}\right)\left(a-b p_{L}+\lambda g_{L}+e_{L}\right)-e_{L}^{2} g_{L}, \\
& \left(p_{L}-\omega_{H}\right)\left(a-b p_{L}+\lambda g_{L}+e_{L}\right)-e_{L}^{2} g_{L} \geq\left(p_{H}-\omega_{L}\right)\left(a-b p_{H}+\lambda g_{H}+e_{H}\right)-e_{H}^{2} g_{H},
\end{aligned}
$$

where $\pi_{0}$ is the retailer's retained profit, and constraints (4) and (5) are the participation constraints which indicate that the retailer can accept the manufacturer's commission when the retailer's profit is greater than the retained profit. Constraints (6) and (7) are incentive constraints and indicate that the retailer can maximize profit by choosing a contract that corresponds to their own type of selling cost.

\section{Proposition 1}

(a) The manufacturer's optimal wholesale price and the optimal product greenness level are expressed as follows:

$$
\begin{aligned}
& \omega_{H}^{N G^{*}}=\frac{a \lambda+b(2 v+1)\left(2 v^{2}+a\right)}{a^{2}+8 b z}, \\
& \omega_{L}^{N G^{*}}=\frac{a \lambda+a(v-1)^{2}\left(b+v^{2}\right)}{a^{2}+8 b z}, \\
& g_{H}^{N G^{*}}=\frac{4 a z \lambda+(1-v)\left(a+4 b v^{2}\right)}{a^{2}+8 b z}, \\
& g_{L}^{N G^{*}}=\frac{4 a z(1-v)\left(4 z v+b v^{2}\right)}{a^{2}+8 b z} .
\end{aligned}
$$

(b) The retailer's optimal level of selling effort and the optimal selling price are expressed as follows:

$$
\begin{aligned}
e_{H}^{N G^{*}}= & \frac{3 \lambda+2 b v(v+1)}{a^{2}+8 b z}, \\
e_{L}^{N G^{*}}= & \frac{\lambda+b v(v+1)}{a^{2}+8 b z}, \\
p_{L}^{N G^{*}}= & \frac{1}{2 b}\left(a+\frac{4 \lambda a z(1-v)\left(4 z v+b v^{2}\right)}{a^{2}+8 b z}\right. \\
& \left.+\frac{a b \lambda+a b(v-1)^{2}\left(b+v^{2}\right)}{a^{2}+8 b z}\right), \\
p_{H}^{N G^{*}}= & \frac{1}{2 b}\left(a+\frac{4 \lambda a z+(1-v)\left(a+4 b v^{2}\right)}{a^{2}+8 b z}\right. \\
& \left.+\frac{a b \lambda+b^{2}(2 v+1)\left(2 v^{2}+a\right)}{a^{2}+8 b z}\right) .
\end{aligned}
$$

Proof. First, we can obtain the first and second derivatives of $p_{H}^{N G}, e_{H}^{N G}, p_{L}^{N G}, e_{L}^{N G}$ from functions (1) and (2): 


$$
\begin{aligned}
\frac{\partial \pi_{R_{H}}^{N G}}{\partial p_{H}^{N G}} & =-2 b p_{H}^{N G}+a+\lambda g_{H}^{N G}+e_{H}^{N G}+b w_{L}^{N G} ; \\
\frac{\partial^{2} \pi_{R_{H}}^{N G}}{\partial\left(p_{H}^{N G}\right)^{2}} & =-2 b<0, \\
\frac{\partial \pi_{R_{H}}^{N G}}{\partial e_{H}^{N G}} & =\left(p_{H}^{N G}-\omega_{L}^{N G}\right)-2 e_{H}^{N G} g_{H}^{N G} ; \\
\frac{\partial^{2} \pi_{R_{H}}^{N G}}{\partial\left(e_{H}^{N G}\right)^{2}} & =-2 g_{H}^{N G}<0, \\
\frac{\partial \pi_{R_{L}}^{N G}}{\partial p_{L}^{N G}} & =-2 b p_{L}^{N G}+a+\lambda g_{L}^{N G}+e_{L}^{N G}+b w_{H}^{N G} ; \\
\frac{\partial^{2} \pi_{R_{L}}^{N G}}{\partial\left(p_{L}^{N G}\right)^{2}} & =-2 b<0, \\
\frac{\partial \pi_{R_{L}}^{N G}}{\partial e_{L}^{N G}} & =\left(p_{L}^{N G}-\omega_{H}^{N G}\right)-2 e_{L}^{N G} g_{L}^{N G} ;
\end{aligned}
$$

Assuming that the first derivative of the $p_{H}^{N G}, e_{H}^{N G}, p_{L}^{N G}, e_{L}^{N G}$ is equal to zero, we can derive the following:

$$
\begin{aligned}
p_{H}^{N G} & =\frac{a+c g-b w_{L}}{4 b g-1}, \\
e_{H}^{N G} & =\frac{a-b w_{H}+\lambda g}{4 b g-1} \\
p_{L}^{N G} & =\frac{2 a g-w_{L}+2 \lambda g^{2}+2 b g w_{L}}{4 b g-1}, \\
e_{L}^{N G} & =\frac{2 a g-w_{H}+2 \lambda g^{2}+2 b w_{H} g}{4 b g-1} .
\end{aligned}
$$

Taking equation (11) into the manufacturer's profit, we can determine that

$$
\begin{aligned}
\max _{g, \omega_{H}, \omega_{L}} \pi_{M}^{N G}= & v\left\{\omega_{L}\left(a-b \frac{a+c g-b w_{L}}{4 b g-1}+\lambda g+\frac{a-b w_{H}+\lambda g}{4 b g-1}\right)-z g^{2}\right\} \\
& +(1-v)\left\{\omega_{H}\left(a-b \frac{2 a g-w_{L}+2 \lambda g^{2}+2 b g w_{L}}{4 b g-1}+\lambda g+\frac{2 a g-w_{H}+2 \lambda g^{2}+2 b w_{H} g}{4 b g-1}\right)-z g^{2}\right\} .
\end{aligned}
$$

From equation (12), we can obtain the first and second derivatives of $\omega_{H}^{N G}$ and $g_{H}^{N G}$, and the Hessian matrix $H_{1}$ can be expressed as follows:

$$
H_{1}=\left[\begin{array}{cc}
b(v-1) & \frac{-\lambda(v-1)}{2} \\
\frac{-\lambda(v-1)}{2} 2 z(v-1)
\end{array}\right] .
$$

If $\lambda^{2}-2 b z<0$, the Hessian matrix $H_{1}$ is negative, such that $\pi_{M}^{N G}$ is the concave function, while equation (12) has the maximum, so we can obtain the optimal value $\omega_{H}^{N G *}$ and $g_{H}^{N G *}$. On the contrary, from equation (12), we can obtain the first and the second derivatives of $\omega_{L}^{N G}$ and $g_{L}^{N G}$, and the Hessian matrix $\mathrm{H}_{2}$ can be expressed as follows:

$$
H_{2}=\left[\begin{array}{cc}
b(v-1) & \frac{-\lambda(v-1)}{2} \\
\frac{-\lambda(v-1)}{2} & 2 z(v-1)
\end{array}\right]
$$

If $\lambda^{2}-2 b z<0$, the Hessian matrix $\mathrm{H}_{2}$ is negative, such that $\pi_{M}^{N G}$ is the concave function, while equation (12) has the maximum, so we can obtain the optimal value $\omega_{L}^{N G *}$ and $g_{L}^{N G *}$. Thus, we can determine Proposition 1 .

Theorem 1. Assume that the retailer's level of selling effort is represented by asymmetric information. Without the government subsidy strategy and with an increasing green preference among consumers, the wholesale price, manufacturer's product greenness level, retailer's selling effort level, and retailer's selling price continue to increase.

According to Proposition 1 and Theorem 1, we obtain the following managerial insight. Without the government subsidy strategy, the level of selling effort is the retailer's private information, in order to obtain more profit, the manufacturer should invest more in the production of green products and strive to improve the greenness level of the product. The manufacturer should communicate with the retailer so as to motivate them to sell more green products and make more profits. 
4.2. GSCM Game Model with Government Subsidization of the Manufacturer (MG Model). In order to encourage the manufacturer to produce more green products, the government should subsidize the manufacturers. According to Dai et al. (2017) and Yang and Xiao [31], $\theta_{g}$ expresses the unit product subsidy received by the manufacturer. The game model can be constructed as follows.

When the retailer's selling cost is high, its profit function can be expressed as

$$
\max _{p_{H}, e_{H}} \pi_{R_{H}}^{N G}=\left(p_{H}-\omega_{L}\right)\left(a-b p_{H}+\lambda g_{H}+e_{H}\right)-e_{H}^{2} g_{H} .
$$

When the retailer's selling cost is low, its profit function can be expressed as

$$
\max _{p_{L}, e_{L}} \pi_{R_{L}}^{N G}=\left(p_{L}-\omega_{H}\right)\left(a-b p_{L}+\lambda g_{L}+e_{L}\right)-e_{L}^{2} g_{L} .
$$

The manufacturer's profit function can be expressed as

$$
\begin{aligned}
& \max _{g_{H}, g_{L}, \omega_{L}, \omega_{H}} \pi_{M}^{M G}=v\left\{\left(\omega_{L}+\theta g_{H}\right)\left(a-b p_{H}+\lambda g_{H}+e_{H}\right)-z g_{H}^{2}\right\} \\
& +(1-v)\left\{\left(\omega_{H}+\theta g_{L}\right)\left(a-b p_{L}+\lambda g_{L}+e_{L}\right)-z g_{L}^{2}\right\} .
\end{aligned}
$$

The constraints can be expressed as follows:

$$
\begin{aligned}
& \left(p_{H}-\omega_{L}\right)\left(a-b p_{H}+\lambda g_{H}+e_{H}\right)-e_{H}^{2} g_{H} \geq \pi_{0}, \\
& \quad\left(p_{L}-\omega_{H}\right)\left(a-b p_{L}+\lambda g_{L}+e_{L}\right)-e_{L}^{2} g_{L} \geq \pi_{0}, \\
& \left(p_{H}-\omega_{L}\right)\left(a-b p_{H}+\lambda g_{H}+e_{H}\right)-e_{H}^{2} g_{H} \geq\left(p_{L}-\omega_{H}\right)\left(a-b p_{L}+\lambda g_{L}+e_{L}\right)-e_{L}^{2} g_{L}, \\
& \quad\left(p_{L}-\omega_{H}\right)\left(a-b p_{L}+\lambda g_{L}+e_{L}\right)-e_{L}^{2} g_{L} \geq\left(p_{H}-\omega_{L}\right)\left(a-b p_{H}+\lambda g_{H}+e_{H}\right)-e_{H}^{2} g_{H},
\end{aligned}
$$

where $\pi_{0}$ is the retailer's retained profit; constraints (18) and (19) are the participation constraints, which indicate that the retailer can accept the manufacturer's commission when the retailer's profit is greater than the retained profit. Constraints (20) and (21) are incentive constraints, which indicate that the retailer can maximize profit by choosing a contract that corresponds to their own type of selling cost.

\section{Proposition 2}

(a) The manufacturer's optimal wholesale price and the optimal product greenness level are expressed as follows:

$$
\begin{aligned}
& \omega_{H}^{M G *}=\frac{a \lambda-b \theta+b(2 v+1)\left(2 v^{2}+a\right)}{a^{2}+8 b z}, \\
& \omega_{L}^{M G *}=\frac{a \lambda-b \theta+a(v-1)^{2}\left(b+v^{2}\right)}{a^{2}+8 b z}, \\
& g_{H}^{M G *}=\frac{4 z b \theta \lambda+4 a z+(1-v)\left(a+4 b v^{2}\right)}{a^{2}+8 b z}, \\
& g_{L}^{M G *}=\frac{4 z b \lambda \theta+4 a z\left(4 z v+b v^{2}\right)}{a^{2}+8 b z} .
\end{aligned}
$$

(b) The retailer's optimal selling effort level and the optimal selling price can be expressed as follows:

$$
\begin{aligned}
e_{H}^{M G *}= & \frac{3 \lambda+2 b v(v+1)+4 v \theta^{2}}{a^{2}+8 b z}, \\
e_{L}^{M G *}= & \frac{\lambda+b v(v+1)+2 v \theta}{a^{2}+8 b z}, \\
p_{L}^{M G *}= & \frac{1}{2 b}\left(a+\frac{4 z b \lambda^{2} \theta+4 a z \lambda\left(4 z v+b v^{2}\right)}{a^{2}+8 b z}\right. \\
& \left.+\frac{a b \lambda+4 b^{2} \theta+a b(v-1)^{2}\left(b+v^{2}\right)}{a^{2}+8 b z}\right), \\
p_{H}^{M G *}= & \frac{1}{2 b}\left(a+\frac{4 z b \theta \lambda^{2}+4 a z \lambda+\lambda(1-v)\left(a+4 b v^{2}\right)}{a^{2}+8 b z}\right. \\
& \left.+\frac{a b \lambda+4 b^{2} \theta+b^{2}(2 v+1)\left(2 v^{2}+a\right)}{a^{2}+8 b z}\right) .
\end{aligned}
$$

The proof process is similar to that of Proposition 1.

Theorem 2. Assume that the retailer's level of selling effort is represented by asymmetric information. Considering that the government subsidizes the manufacturer, and given increasing green preferences among consumers, there is an increase in the wholesale price, the manufacturer's product greenness level, the retailer's level of selling effort, and retailer's selling price. 
Theorem 3. Assume that the retailer's level of selling effort is represented by asymmetric information. Considering that the government subsidizes the manufacturer, and given a higher unit product subsidy coefficient, there is an increase in the manufacturer's product greenness level, the retailer's selling effort level, and the retailer's selling price. However, the manufacturer's wholesale price decreases.

According to Proposition 2 and Theorems 2 and 3, we obtain the following managerial insight. When the government subsidizes the manufacturer, the manufacturer obtains the subsidy so that the manufacturer can reduce the wholesale price of green products. In this way, the purchase cost of the retailer can be reduced so that the retailer can be more effectively encouraged to sell more green products. As a result, the manufacturer can obtain much more profit.

4.3. GSCM Game Model with Government Subsidization of the Retailer (MG Model). The government encourages the retailer to sell more green products. Based on the retailer's selling cost, the government subsidizes the retailer. The total amount of subsidies received by the retailer can be expressed as $\mu e^{2} \mathrm{~g}$. The game model can be constructed as follows.

When the retailer's selling cost is high, its profit function can be expressed as

$$
\max _{p_{H}, e_{H}} \pi_{R_{H}}^{N G}=\left(p_{H}-\omega_{L}\right)\left(a-b p_{H}+\lambda g_{H}+e_{H}\right)+(\mu-1) e_{H}^{2} g_{H} \text {. }
$$

When the retailer's selling cost is low, its profit function can be expressed as

$$
\max _{p_{L}, e_{L}} \pi_{R_{L}}^{N G}=\left(p_{L}-\omega_{H}\right)\left(a-b p_{L}+\lambda g_{L}+e_{L}\right)+(\mu-1) e_{L}^{2} g_{L}
$$

The manufacturer's profit function can be expressed as

$$
\begin{aligned}
\max _{g_{H}, g_{L}, \omega_{L}, \omega_{H}} \pi_{M}^{M G}= & v\left\{\omega_{L}\left(a-b p_{H}+\lambda g_{H}+e_{H}\right)-z g_{H}^{2}\right\} \\
& +(1-v)\left\{\omega_{H}\left(a-b p_{L}+\lambda g_{L}+e_{L}\right)-z g_{L}^{2}\right\} .
\end{aligned}
$$

The constraints can be expressed as follows:

$$
\begin{aligned}
& \left(p_{H}-\omega_{L}\right)\left(a-b p_{H}+\lambda g_{H}+e_{H}\right)+(\mu-1) e_{H}^{2} g_{H} \geq \pi_{0}, \\
& \quad\left(p_{L}-\omega_{H}\right)\left(a-b p_{L}+\lambda g_{L}+e_{L}\right)+(\mu-1) e_{L}^{2} g_{L} \geq \pi_{0}, \\
& \left(p_{H}-\omega_{L}\right)\left(a-b p_{H}+\lambda g_{H}+e_{H}\right)+(\mu-1) e_{H}^{2} g_{H} \geq\left(p_{L}-\omega_{H}\right)\left(a-b p_{L}+\lambda g_{L}+e_{L}\right)+(\mu-1) e_{L}^{2} g_{L}, \\
& \quad\left(p_{L}-\omega_{H}\right)\left(a-b p_{L}+\lambda g_{L}+e_{L}\right)+(\mu-1) e_{L}^{2} g_{L} \geq\left(p_{H}-\omega_{L}\right)\left(a-b p_{H}+\lambda g_{H}+e_{H}\right)+(\mu-1) e_{H}^{2} g_{H},
\end{aligned}
$$

where $\pi_{0}$ is the retailer's retained profit; constraints (27) and (28) are the participation constraints which indicate that the retailer can accept the manufacturer's commission when the retailer's profit is greater than the retained profit. Constraints (29) and (30) are incentive constraints which indicate that the retailer can maximize profit by choosing a contract that corresponds to their own type of selling cost.

\section{Proposition 3}

(a) The manufacturer's optimal wholesale price and the optimal product greenness level can be expressed as follows:

$$
\begin{aligned}
& \omega_{H}^{R G^{*}}=\frac{a \lambda-4 b \mu+b(2 v+1)\left(2 v^{2}+a\right)}{a^{2}+8 b z}, \\
& \omega_{L}^{R G^{*}}=\frac{a \lambda-4 b \mu+a(v-1)^{2}\left(b+v^{2}\right)}{a^{2}+8 b z}, \\
& g_{H}^{R G^{*}}=\frac{2 \lambda \mu+4 a z+(1-v)\left(a+4 b v^{2}\right)}{a^{2}+8 b z}, \\
& g_{L}^{R G^{*}}=\frac{2 \lambda \mu+4 a z\left(4 z v+b v^{2}\right)}{a^{2}+8 b z} .
\end{aligned}
$$

(b) The retailer's optimal level of selling effort and the optimal selling price are expressed as follows:

$$
e_{H}^{R G^{*}}=\frac{3 \lambda+2 b v(v+1)+2 v \mu}{a^{2}+8 b z}
$$$$
e_{L}^{R G^{*}}=\frac{\lambda+b v(v+1)+v \mu}{a^{2}+8 b z},
$$$$
p_{L}^{R G^{*}}=\frac{1}{2 b}\left(a+\frac{2 \lambda^{2} \mu+4 a z \lambda\left(4 z v+b v^{2}\right)}{a^{2}+8 b z}\right.
$$

$$
\left.+\frac{a b \lambda+b^{2} \lambda \mu+a b(v-1)^{2}\left(b+v^{2}\right)}{a^{2}+8 b z}\right),
$$

$$
\begin{aligned}
p_{H}^{R G^{*}}= & \frac{1}{2 b}\left(a+\frac{2 \lambda^{2} \mu+4 a z \lambda+\lambda(1-v)\left(a+4 b v^{2}\right)}{a^{2}+8 b z}\right. \\
& \left.+\frac{a b \lambda+b^{2} \lambda \mu+b^{2}(2 v+1)\left(2 v^{2}+a\right)}{a^{2}+8 b z}\right) .
\end{aligned}
$$

The proof process is similar that of Proposition 1. 
Theorem 4. Assume that the retailer's selling effort is represented by asymmetric information. Considering that the government subsidizes the retailer, and given increasing green preferences among consumers, there is an increase in the wholesale price, the manufacturer's product greenness level, the retailer's selling effort level, and the retailer's selling price.

Theorem 5. Assume that the retailer's level of selling effort is represented by asymmetric information. Considering that the government subsidizes the retailer, and given the increasing coefficient of the selling cost subsidy, there is an increase in the manufacturer's product greenness level, the retailer's selling effort level, and the retailer's selling price. However, the manufacturer's wholesale price decreases.

According to Proposition 3 and Theorems 4 and 5, we obtain the following managerial insight. When the green preferences among consumers is higher, on the one hand, the manufacturer should improve the investment and increase the greenness level of the product, so that it can meet the consumer's demand. On the other hand, the retailer gets the government's subsidy, and it can improve the selling effort level and enlarge the selling quantity of green products. As a result, the manufacturer and the retailer can obtain much more profit.

\section{Result Analysis and Management Implications}

5.1. Comparative Basis. Based on Theorems 3 and 5, the government subsidy not only improves the degree of greenness but also increases the retailer's level of selling effort and the retailer's selling price. Based on the same government subsidy expenditure, we can compare and analyze the different effects of the two types of subsidy strategies. The total government subsidy expenditure under the two types of subsidy strategies can be expressed as follows:

$$
\begin{aligned}
& E_{(\theta)}^{M G *}=\frac{\theta\left(a+3 b \lambda+b^{2}+(2 v+1)\left(v^{2}+2\right)\right)}{(a+8 b z)^{3}}, \\
& E_{(\mu)}^{R G^{*}}=\frac{\mu(3 \lambda+2 b v(v+1)+2 v)\left(4 a z+(1-v)\left(a+4 b v^{2}\right)\right)}{\left(a^{2}+8 b z\right)^{3}} .
\end{aligned}
$$

In order to get the same amount of government subsidy expenditure, it makes the comparison more meaningful. The parameters $\theta$ and $\mu$ should satisfy a quantitative relationship. Assuming that $E_{(\theta)}^{M G *}=E_{(\mu)}^{R G^{*}}$, we can obtain the value $\mu(\theta)^{R G^{*}}$ which can be expressed as follows:

$$
\mu(\theta)^{R G^{*}}=\frac{\theta\left(a+3 b \lambda+b^{2}+(2 v+1)\left(v^{2}+2\right)\right)}{(3 \lambda+2 b v(v+1)+2 v)\left(4 a z+(1-v)\left(a+4 b v^{2}\right)\right)} .
$$

5.2. Comparative Analysis. The reasons as to why the government would subsidize the enterprise in GSCM can be explained as follows: on the one hand, the government can improve the greenness of the products produced by the manufacturer; on the other hand, it can encourage the retailer to sell more green products. Based on the above analysis, the optimal solutions of GSCM in each of the three situations can be compared and analyzed, and it is beneficial to examine the different effects of government subsidy strategies. We can derive the following corollaries.

Corollary 1. Under the same amount of government subsidy expenditure, when the retailer's level of selling effort is high, there is a negative relationship between the coefficient of the unit product subsidy received by manufacturer and the wholesale price. There is a positive relationship between the coefficient of the unit product subsidy received by the manufacturer and the product greenness level, the retailer's level of selling effort, and the retailer's selling price. When the retailer's selling effort is low, we arrive at the same conclusion. In addition, when the retailer's level of selling effort is high, there is a negative relationship between the coefficient of the selling cost subsidy received by the retailer and the wholesale price. There is a positive relationship between the coefficient of the selling cost subsidy received by the retailer and the product greenness level, the retailer's level of selling effort, and the retailer's selling price. When the retailer's selling effort is low, we arrive at the same conclusion.

Proof. We can derive the first derivatives of $w_{H}^{M G *}$, $w_{L}^{M G *}, g_{H}^{M G *}, g_{L}^{M G *}, e_{H}^{M G *}, e_{L}^{M G *}, p_{H}^{M G *}$, and $p_{L}^{M G *} \quad$ from Proposition 2, and we can obtain the following:

$$
\begin{aligned}
& \frac{\partial \omega_{H}^{M G *}}{\partial \theta}=-\frac{b}{a^{2}+8 b z}<0, \\
& \frac{\partial \omega_{L}^{M G *}}{\partial \theta}=-\frac{b}{a^{2}+8 b z}<0, \\
& \frac{\partial g_{H}^{M G *}}{\partial \theta}=\frac{4 z b \lambda}{a^{2}+8 b z}>0, \\
& \frac{\partial g_{L}^{M G *}}{\partial \theta}=\frac{4 z b \lambda}{a^{2}+8 b z}>0, \\
& \frac{\partial e_{H}^{M G *}}{\partial \theta}=\frac{8 v \theta}{a^{2}+8 b z}>0, \\
& \frac{\partial e_{L}^{M G *}}{\partial \theta}=\frac{2 v}{a^{2}+8 b z}>0, \\
& \frac{\partial p_{L}^{M G *}}{\partial \theta}=\frac{2 z \lambda^{2}+2 b}{a^{2}+8 b z}>0, \\
& \frac{\partial p_{H}^{M G *}}{\partial \theta}=\frac{2 z \lambda^{2}+2 b}{a^{2}+8 b z}>0 .
\end{aligned}
$$

We can derive the first derivatives of $w_{H}^{R G^{*}}, w_{L}^{R G^{*}}$, $g_{H}^{R G^{*}}, g_{L}^{R G^{*}}, e_{H}^{R G^{*}}, e_{L}^{R G^{*}}, p_{H}^{R G^{*}}$, and $p_{L}^{R G^{*}}$ from Proposition 3, and we can determine the following: 


$$
\begin{aligned}
\frac{\partial \omega_{H}^{R G^{*}}}{\partial \mu} & =-\frac{4 b}{a^{2}+8 b z}<0, \\
\frac{\partial \omega_{L}^{R G^{*}}}{\partial \mu} & =-\frac{4 b}{a^{2}+8 b z}<0, \\
\frac{\partial g_{H}^{R G^{*}}}{\partial \mu} & =\frac{2 \lambda}{a^{2}+8 b z}>0, \\
\frac{\partial g_{L}^{R G^{*}}}{\partial \theta} & =\frac{2 \lambda}{a^{2}+8 b z}>0, \\
\frac{\partial e_{H}^{R G^{*}}}{\partial \mu} & =\frac{2 v}{a^{2}+8 b z}>0, \\
\frac{\partial e_{L}^{R G^{*}}}{\partial \mu} & =\frac{v}{a^{2}+8 b z}>0, \\
\frac{\partial p_{L}^{R G^{*}}}{\partial \mu} & =\frac{1}{2 b}\left(\frac{2 \lambda^{2}+b^{2} \lambda}{a^{2}+8 b z}\right)>0, \\
\frac{\partial p_{H}^{R G^{*}}}{\partial \theta} & =\frac{1}{2 b}\left(\frac{2 \lambda^{2}+b^{2} \lambda}{a^{2}+8 b z}\right)>0 .
\end{aligned}
$$

Thus, we can obtain Corollary 1.

Corollary 2. Under the same amount of government subsidy expenditure, and when the retailer's level of selling effort is high, under different situations, the manufacturer's optimal wholesale price has the following inequality $\omega_{H}^{N G^{*}}>\omega_{H}^{R G^{*}}>\omega_{H}^{M G^{*}}$. When the retailer's level of selling effort is low, under different situations, the manufacturer's optimal wholesale price has the following inequality $\omega_{L}^{N G^{*}}>\omega_{L}^{R G^{*}}>\omega_{L}^{M G^{*}}$.

Corollary 2 shows that the government's subsidy strategy can lower the manufacturer's wholesale price. On the one hand, without the government subsidy strategy, the manufacturer must improve the wholesale price in order to obtain higher profits. Under the government subsidy strategy, the manufacturer can receive certain economic compensation from the government so that the manufacturer can lower the wholesale price. However, when the government subsidizes the manufacturer, the wholesale price is lower than that which would be observed in the case of government subsidization of the retailer.

Corollary 3. Under the same amount of government subsidy expenditure, when the retailer's level of selling effort is high, under different situations, the manufacturer's optimal level of greenness has the following inequality $g_{H}^{N G^{*}}<g_{H}^{R G^{*}}<g_{H}^{M G^{*}}$. When the retailer's level of selling effort is low, under different situations, the manufacturer's optimal greenness level has the following inequality $g_{L}^{N G^{*}}<g_{L}^{R G^{*}}<g_{L}^{M G^{*}}$.

Corollary 3 shows that the government's subsidy strategy can improve the manufacturer's greenness level. On the one hand, without the government subsidy strategy, the manufacturer can reduce the cost to earn more money, which can result in a lower greenness level. Under the government subsidy strategy, the manufacturer can receive certain economic compensation from the government so that the manufacturer can improve the greenness level. On the other hand, when the government subsidizes the manufacturer, the product greenness level is higher than that which would be observed when the government subsidizes the retailer. From the perspective of the level of product greenness, the government's subsidization of the manufacturer is more effective than subsidization of the retailer.

Corollary 4. Under the same amount of government subsidy expenditure, when the retailer's level of selling effort is high, the retailer's optimal selling effort has the following inequality $e_{H}^{N G^{*}}<e_{H}^{M G^{*}}<e_{H}^{R G^{*}}$. When the retailer's level of selling effort is low, the retailer's optimal selling effort has the following inequality $e_{L}^{N G^{*}}<e_{L}^{M G^{*}}<e_{L}^{R G^{*}}$.

Corollary 4 shows that the government's subsidy strategy can improve the retailer's selling effort. In order to increase the quantity of sales, the retailer needs to improve their level of selling effort, which can lead to higher selling costs for the retailer. Under the government subsidy strategy, the retailer is able to improve their selling effort. However, under the same amount of government subsidy expenditure, the retailer can benefit from the government subsidy strategy. Thus, it can strongly motivate the retailer to sell more products. From the perspective of the level of selling effort, government subsidization of the retailer is more effective than subsidization of the manufacturer.

5.3. Numerical Analysis. The impact of the government subsidy strategy on the manufacturer's and retailer's profit can be analyzed using numerical analysis. Assuming $a=200, b=10, \rho=0.4, z=2$, and $v=4$. The corresponding value of subsidy parameters is shown in Table 1.

Under two different types of government subsidy strategy, the impact of different subsidy parameters on the wholesale price, greenness level, selling price, level of selling effort, and manufacturer's and retailer's profit is shown in Figures 2-7.

As shown in Figure 2, whether the retailer's level of selling effort is either high or low, the manufacturer's wholesale price shows a downward trend in the $M G$ and $R G$ models. Moreover, when the retailer's level of selling effort is high, the manufacturer's wholesale price is higher than when the retailer's level of selling effort is low. The manufacturer can receive some economic compensation. Thus, the manufacturer's wholesale price can decrease under the government subsidy strategy. Furthermore, the manufacturer's wholesale price is at the highest level in the $R G$ model, while it is at its lowest level in the $M G$ model. This indicates that government subsidization of the manufacturer is more effective than subsidization of the retailer.

As shown in Figure 3, regardless of whether the retailer's level of selling effort is high or low, as the government subsidy coefficient increases, the greenness level increases in the $M G$ and $R G$ models. Moreover, when the retailer's level of selling effort is high, the greenness level is higher than 
TABLE 1: The corresponding value of subsidy parameters under the same government subsidy expenditure.

\begin{tabular}{lcccccccccc}
\hline$\theta$ & 0.1 & 0.2 & 0.3 & 0.4 & 0.5 & 0.6 & 0.7 & 0.8 & 0.9 & 1 \\
$\mu(\theta)^{R G^{*}}$ & 0.15 & 0.27 & 0.31 & 0.44 & 0.521 & 0.684 & 0.781 & 0.88 & 0.914 & 1.21 \\
\hline
\end{tabular}

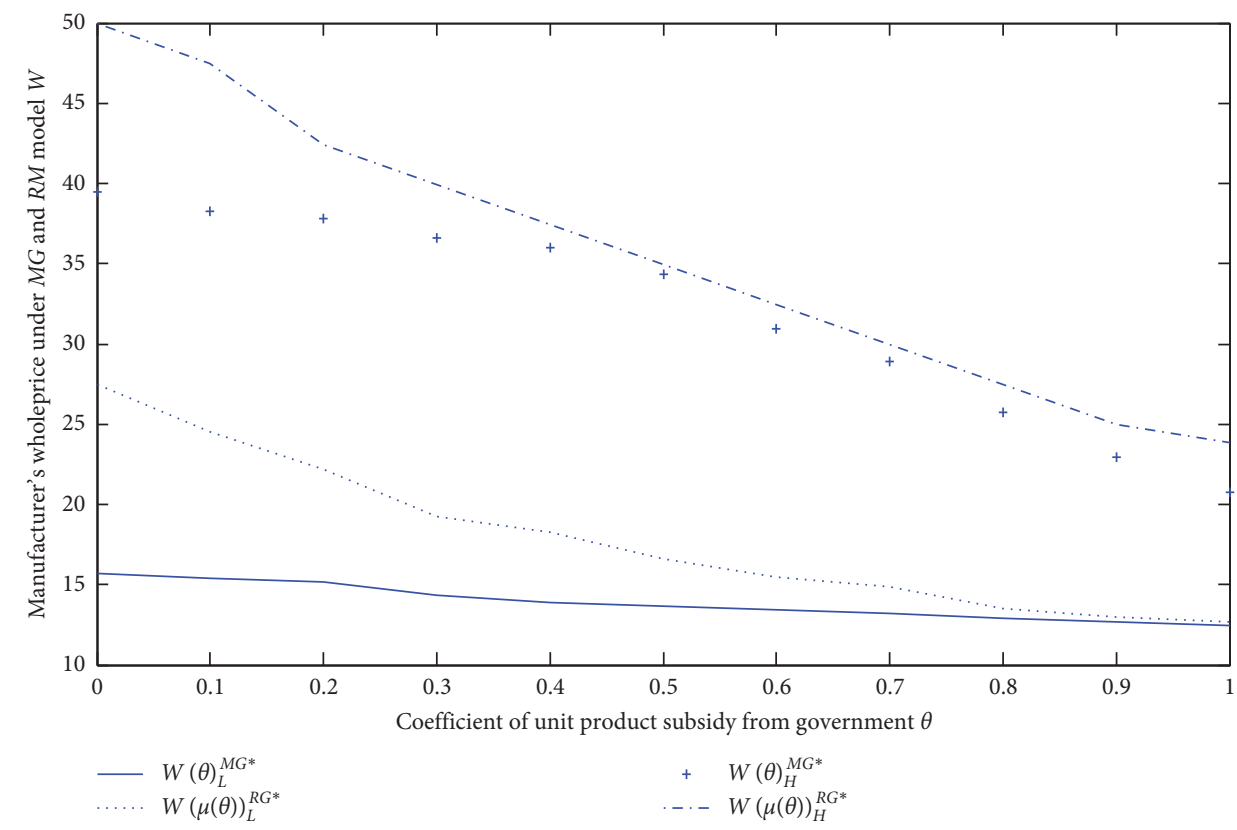

FIGURE 2: The impact of different government subsidy coefficients on the manufacturer's wholesale price under two models.

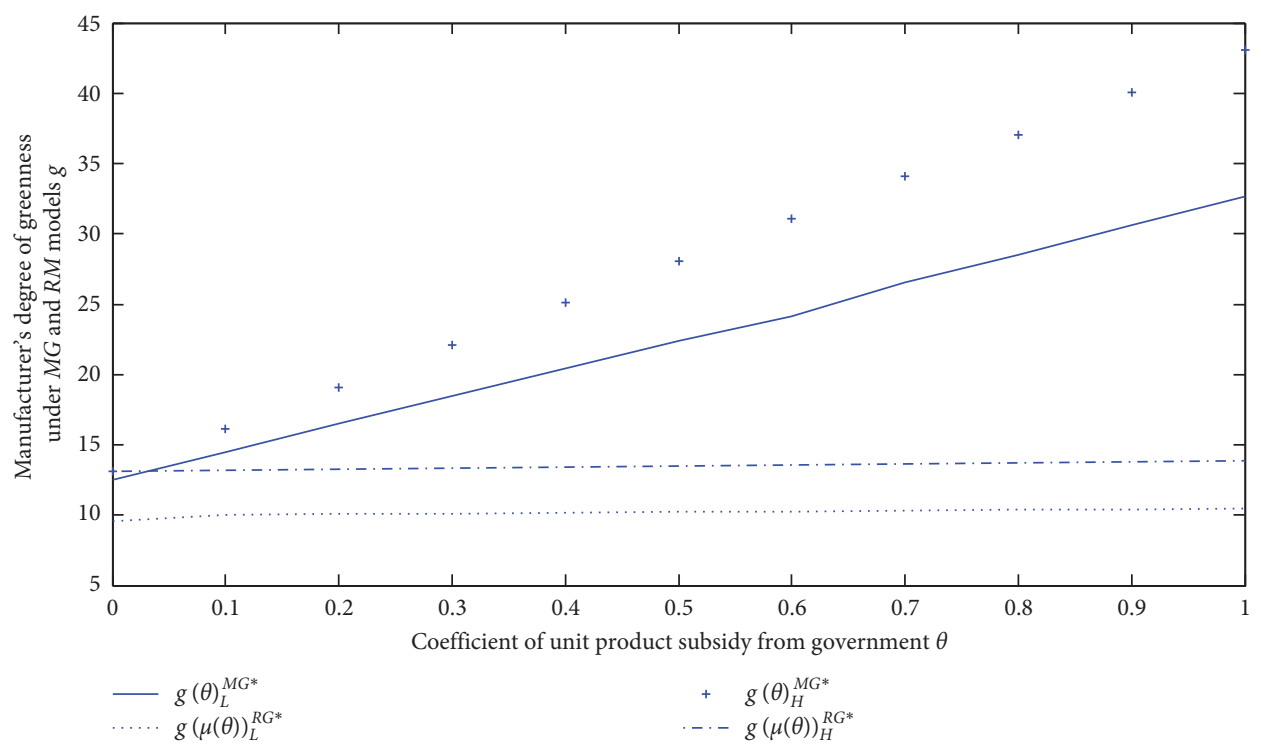

Figure 3: The impact of different government subsidy coefficients on the manufacturer's greenness level under two models.

when the retailer's level of selling effort is low. The manufacturer can benefit from two types of government subsidy strategy. The manufacturer is in a position to increase its investment in the research and development of green products, and it can improve the product greenness level. However, the greenness level in the $M G$ model is higher than that in the $R G$ model. From the perspective of improving the greenness level, this indicates that the government's subsidization of the manufacturer is more effective than subsidization of the retailer.

As shown in Figure 4, regardless of whether the retailer's level of selling effort is high or low, as the government 


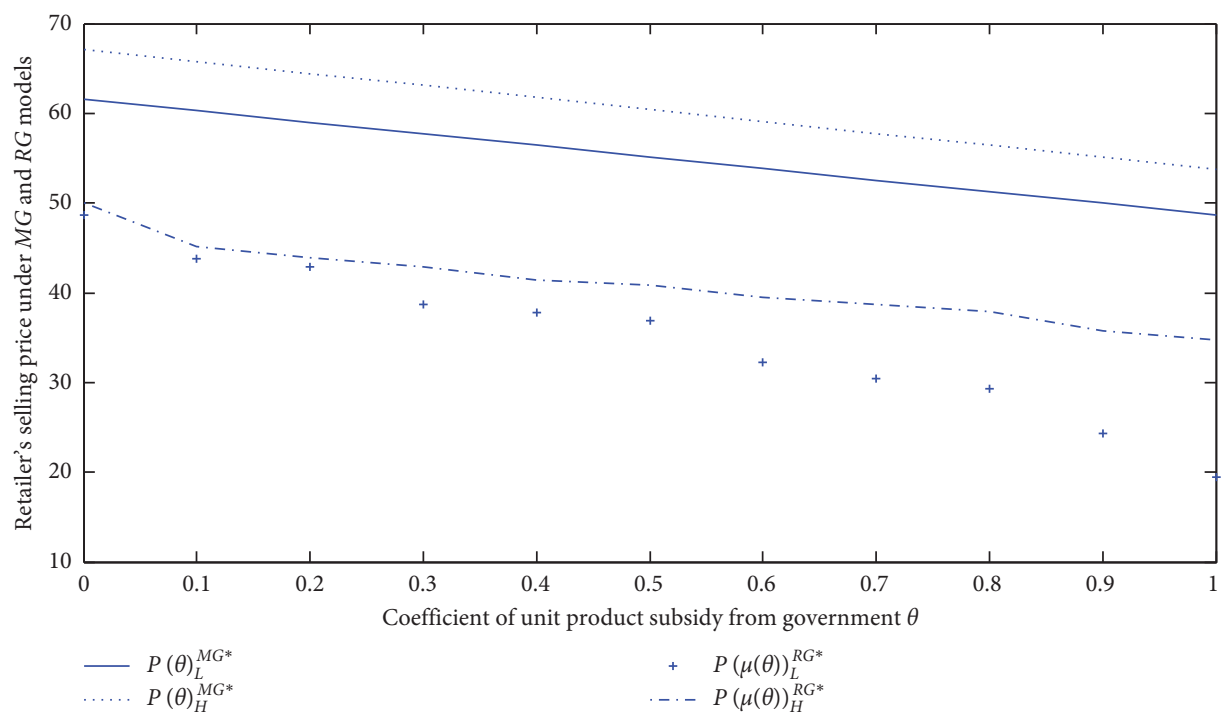

FIGURE 4: The impact of different government subsidy coefficients on retailer's selling price under two models.

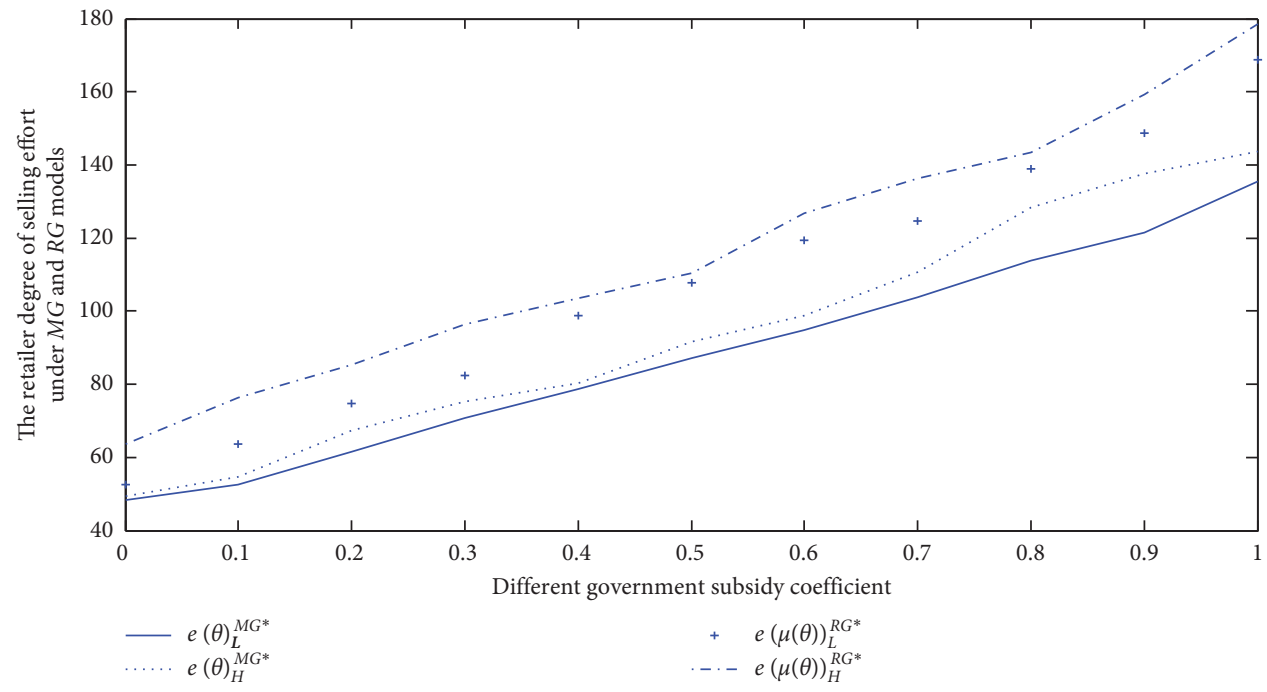

FIGURE 5: The impact of different government subsidy coefficients on retailer's level of selling effort under two models.

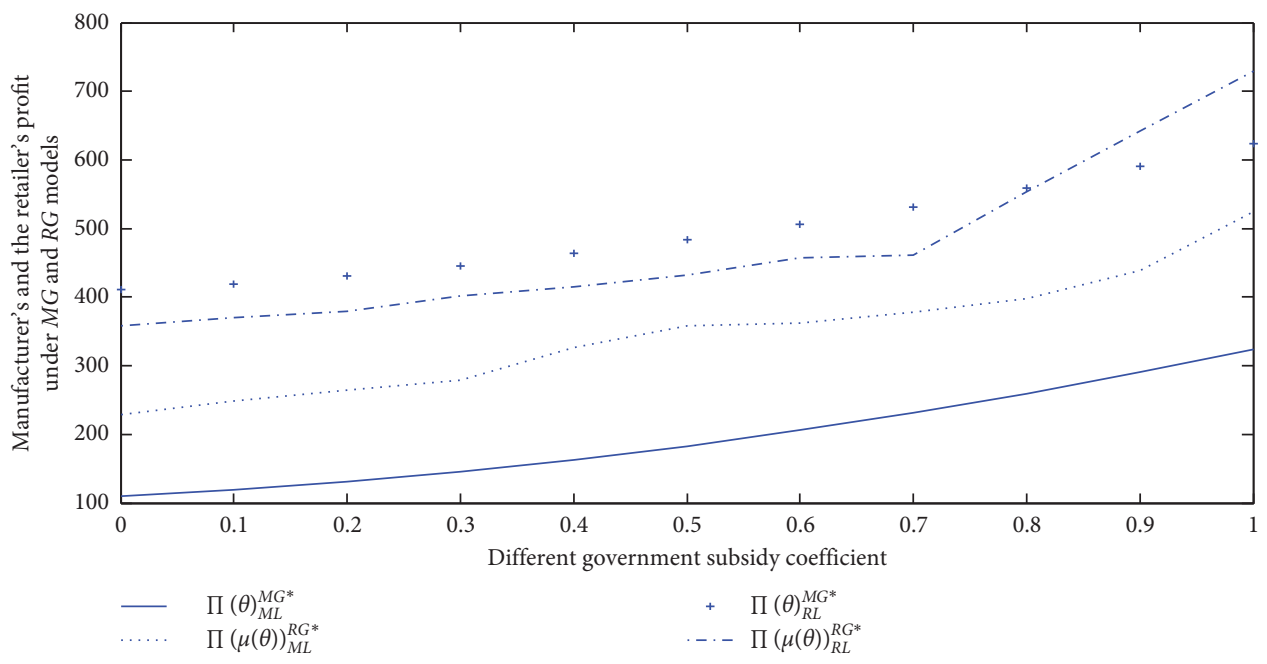

FIGURE 6: The impact of different government subsidy coefficients on the enterprise's profit when the selling effort level is low. 


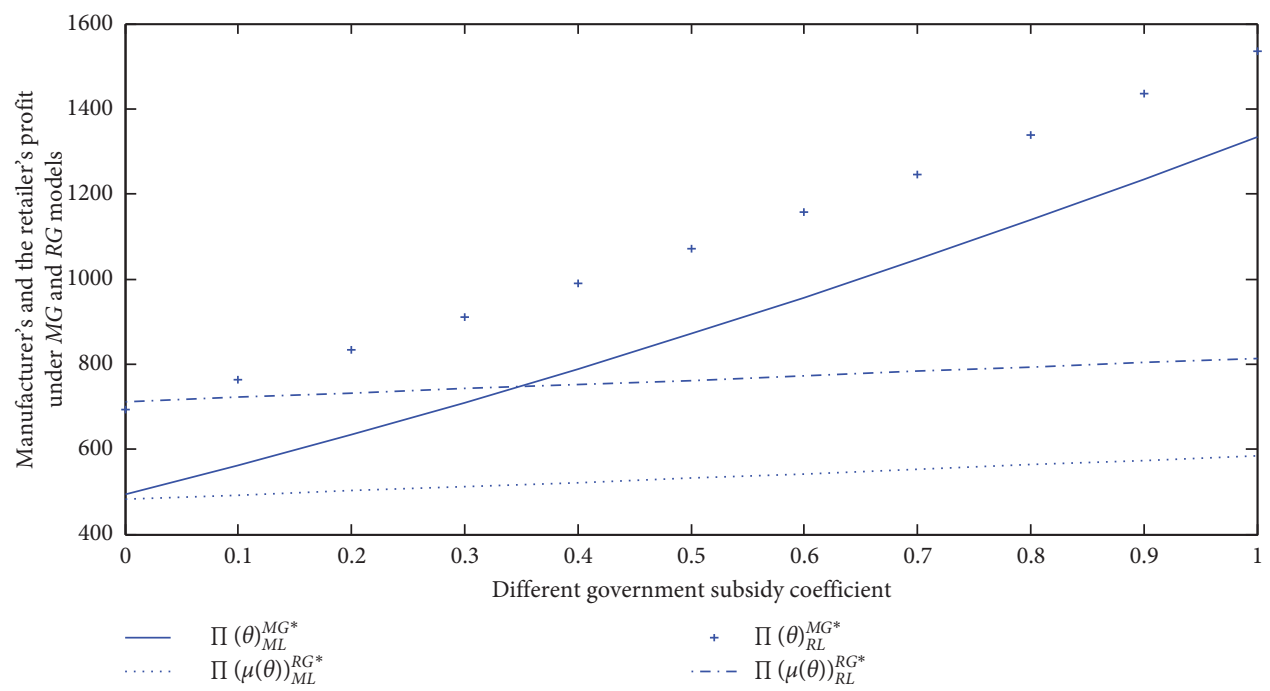

Figure 7: The impact of different government subsidy coefficients on the enterprise's profit when the level of selling effort is high.

subsidy coefficient increases, the retailer's selling price shows a downward trend in the $M G$ and $R G$ models. The retailer's selling price is at the lowest level under the $R G$ model and at the highest level under the $M G$ model. In addition, when the retailer's level of selling effort is high, the retailer's selling price is higher than when the retailer's level of selling effort is low. From the perspective of improving the retailer's selling price, this indicates that the government's subsidization of the retailer is more effective than subsidization of the manufacturer.

As shown in Figure 5, as the government subsidy coefficient increases, the retailer's level of selling effort increases under two types of government subsidy strategy. The retailer's level of selling effort under the $R G$ model is higher than that under the $M G$ model. It is more obvious that the government subsidizes the retailer so that it can improve the retailer's level of selling effort.

As shown in Figures 6 and 7, when the retailer's level of selling effort is low, and as the government subsidy coefficient increases, both the manufacturer and retailer's profit increases. For the manufacturer, its profit in the $R G$ model is higher than that in the $M G$ model. On the contrary, for the retailer, when it satisfies the condition $\theta \in[0,0.8]$, the retailer's profit in the $M G$ model is higher than that in the $R G$ model. When it satisfies the condition $\theta \in[0.8,1]$, the retailer's profit in the $R G$ model is higher than that in the $M G$ model. Moreover, when the retailer's level of selling effort is high, the manufacturer's profit in the $M G$ model is higher than that in the $R G$ model; the retailer's profit in the $M G$ model is higher than that in the $R G$ model.

\section{Conclusions and Future Research}

This study examined a two level green supply chain system with one manufacturer and one retailer, in which the market demand was mainly affected by the product greenness level, the level of selling effort, and the selling price. First, it was assumed that the retailer's level of selling effort was represented by asymmetric information, and that the manufacturer designed incentive contracts to induce the retailer to disclose private information by using the principal-agent theory. Second, the game models, both without a government subsidy strategy and with two types of government subsidy strategies, were constructed. The optimal solution of the wholesale price, the greenness level, the selling price, the level of selling effort, and the manufacturer and the retailer's profit was obtained. Finally, we arrived at the following conclusions: (1) the government subsidy strategy improves not only the greenness level but also the manufacturer and retailer's profit; (2) regardless of whether the retailer's level of selling effort is high or low, as the government subsidy coefficient increases, the wholesale price, greenness level, and the level of selling effort increases; (3) when the retailer's level of selling effort is low, and as the government subsidy coefficient increases, the manufacturer and retailer's profit increase. For the manufacturer, its profit in the $R G$ model is higher than that in the $M G$ model. Moreover, when the retailer's level of selling effort is high, the manufacturer's profit in the $M G$ model is higher than that in the $R G$ model; the retailer's profit in the $M G$ model is higher than that in the $R G$ model.

In the paper, we only considered the green supply chain game dominated by the manufacturer. We did not consider the green supply chain game dominated by the retailer. This study explored the impact of government subsidy strategies on the green supply chain. This paper did not consider the impact of a government carbon tax strategy or a rewardpenalty mechanism on the green supply chain. We aim to evaluate these issues in future research.

\section{Data Availability}

The data used to support the findings of this study are not included within the article and are available from the corresponding author. 


\section{Conflicts of Interest}

The authors declare that there are no conflicts of interest.

\section{Authors' Contributions}

Y. X. and Z. X. conceptualized the study. Y. X. wrote the original study. Z. D. reviewed and edited the article. Y. X provided funding acquisition.

\section{Acknowledgments}

This work was supported by the National Natural Science Foundation of China (nos. 7150116, 71502037, and 71103149), the Natural Science Foundation of University in Jiangsu Province (no. 19KJB120006), the outstanding Doctor Scientific Research Fund Project at Jiangsu Normal University (no. 18XWRS008), and a project funded by the priority academic program development of Jiangsu Higher Education Instituations (PADP). The authors thank International Science Editing (http://www.international science editing.com) for editing this manuscript.

\section{References}

[1] B. Chekima, S. A. W. Syed Khalid Wafa, O. A. Igau, S. Chekima, and S. L. Sondoh, "Examining green consumerism motivational drivers: does premium price and demographics matter to green purchasing?" Journal of Cleaner Production, vol. 112, pp. 3436-3450, 2016.

[2] S. Zhao, Q. Zhu, and L. Cui, "A decision-making model for remanufacturers: considering both consumers' environmental preference and the government subsidy policy," Resources, Conservation and Recycling, vol. 128, pp. 176-186, 2018.

[3] S. Barari, G. Agarwal, W. J. Zhang, B. Mahanty, and M. K. Tiwari, "A decision framework for the analysis of green supply chain contracts: an evolutionary game approach," Expert System with Application, vol. 39, no. 3, pp. 2965-2976, 2012.

[4] M. Runkel, "Product durability and extended producer responsibility in solid waste management," Environmental and Resource Economics, vol. 24, no. 2, pp. 161-182, 2003.

[5] D. Aksen, N. Aras, and A. G. Karaarslan, "Design and analysis of government subsidized collection systems for incentivedependent returns," International Journal of Production Economics, vol. 119, no. 2, pp. 308-327, 2009.

[6] J.-B. Sheu, "Bargaining framework for competitive green supply chains under governmental financial intervention," Transportation Research Part E: Logistics and Transportation Review, vol. 47, no. 5, pp. 573-592, 2011.

[7] W.-m. Ma, Z. Zhao, and H. Ke, "Dual-channel closed-loop supply chain with government consumption-subsidy," European Journal of Operational Research, vol. 226, no. 2, pp. 221-227, 2013.

[8] S. Benjaafar, Y. Li, and M. Daskin, "Carbon footprint and the management of supply chains: insights from simple models," IEEE Transactions on Automation Science and Engineering, vol. 10, no. 1, pp. 99-116, 2013.

[9] A. Toptal, H. Özlü, and D. Konur, "Joint decisions on inventory replenishment and emission reduction investment under different emission regulations," International Journal of Production Research, vol. 52, no. 1, pp. 243-269, 2014.
[10] X. Chen, X. Wang, V. Kumar, and N. Kumar, "Low carbon warehouse management under cap-and-trade policy," Journal of Cleaner Production, vol. 139, pp. 894-904, 2016.

[11] W. T. Chen, Z. H. Hu, and C. Yu, "A model of green supply chain with reward and punishment mechanism under different government target decisions," Control and Decision Making, vol. 32, no. 1, pp. 5-14, 2018.

[12] K. Kang, Y. Zhao, Y. Ma, and Z. Li, "Green supply chain poverty alleviation through microfinance game model and cooperative analysis," Journal of Cleaner Production, vol. 226, no. 5, pp. 1022-1041, 2019.

[13] P. He, Y. He, and H. Xu, "Channel structure and pricing in a dual-channel closed-loop supply chain with government subsidy," International Journal of Production Economics, vol. 213, no. 3, pp. 108-123, 2019.

[14] J. Huang, M. Leng, L. Liang, and J. Liu, "Promoting electric automobiles: supply chain analysis under a government's subsidy incentive scheme," IIE Transactions, vol. 45, no. 8, pp. 826-844, 2013.

[15] A. Zakeri, F. Dehghanian, B. Fahimnia, and J. Sarkis, "Carbon pricing versus emissions trading: a supply chain planning perspective," International Journal of Production Economics, vol. 164, pp. 197-205, 2015.

[16] Y. D. Li, X. P. Xie, and G. Ying, "Research on cooperative emission reduction decision-making mechanism of supply chain enterprises under two sharing contracts," Journal of Chinese Management Science, vol. 24, no. 3, pp. 61-70, 2016.

[17] B. Li, M. Zhu, and Y. Jiang, "Pricing policies of a competitive dual-channel green supply chain," Journal of Cleaner Production, vol. 112, pp. 2029-2042, 2016.

[18] W. Li and Z.-H. Hu, "Using evolutionary game theory to study governments and manufacturers' behavioral strategies under various carbon taxes and subsidies," Journal of Cleaner Production, vol. 201, no. 5, pp. 123-141, 2018.

[19] H. Zhang, J. M. Huang, and Y. Y. Cui, "Considering the game model and contract coordination of green supply chain with fair preference under government subsidies," Industrial Technology Economy, vol. 291, no. 1, pp. 111-122, 2018.

[20] A. Gharaei, M. Karimi, and S. A. Hoseini Shekarabi, "An integrated multi-product, multi-buyer supply chain under penalty, green, and quality control polices and a vendor managed inventory with consignment stock agreement: the outer approximation with equality relaxation and augmented penalty algorithm," Applied Mathematical Modelling, vol. 69, pp. 223-254, 2019.

[21] Y. Tian, K. Govindan, and Q. Zhu, "A system dynamics model based on evolutionary game theory for green supply chain management diffusion among Chinese manufacturers," Journal of Cleaner Production, vol. 80, pp. 96-105, 2014.

[22] W. B. Wang, S. Y. Zhou, M. Zhang, H. Sun, and L. Y. He, “A closed-loop supply chain with competitive dual collection channel under asymmetric information and reward-penalty mechanism," Sustainability, vol. 10, p. 2031, 2018.

[23] J. F. Su, C. Li, Q. J. Zeng, J. Q. Yang, and J. Zhang, "A green closed-loop supply chain coordination mechanism based on third-party recycling," Sustainability, vol. 11, pp. 1-14, 2019.

[24] H. Sun, Y. Wan, L. Zhang, and Z. Zhou, "Evolutionary game of the green investment in a two-echelon supply chain under a government subsidy mechanism," Journal of Cleaner Production, vol. 235, pp. 1315-1326, 2019.

[25] P. He, Y. He, H. Xu, and L. Zhou, "Online selling mode choice and pricing in an $\mathrm{O} 2 \mathrm{O}$ tourism supply chain considering corporate social responsibility," Electronic Commerce Research and Applications, vol. 38, p. 100894, 2019. 
[26] D. Chen, J. Ignatius, D. Sun, M. Goh, and S. Zhan, "Pricing and equity in cross-regional green supply chains," European Journal of Operational Research, vol. 280, no. 3, pp. 970-987, 2020.

[27] X. Q. Zhang, X. G. Yuan, and D. L. Zhang, "Research on closed-loop supply chain with competing retailers under government reward-penalty mechanism and asymmetric information," Discrete Dynamics in Nature and Society, vol. 2020, Article ID 7587453, 20 pages, 2020.

[28] P. He, Y. He, C. Shi, H. Xu, and L. Zhou, "Cost-sharing contract design in a low-carbon service supply chain," Computers \& Industrial Engineering, vol. 139, p. 106160, 2020.

[29] D. Ghosh and J. Shah, "A comparative analysis of greening policies across supply chain structures," International Journal of Production Economics, vol. 135, no. 2, pp. 568-583, 2012.

[30] D. Ghosh and J. Shah, "Supply chain analysis under green sensitive consumer demand and cost sharing contract," International Journal of Production Economics, vol. 164, pp. 319-329, 2015.

[31] D. Yang and T. Xiao, "Pricing and green level decisions of a green supply chain with governmental interventions under fuzzy uncertainties," Journal of Cleaner Production, vol. 149, pp. 1174-1187, 2017.

[32] Q. Zhu and Y. Dou, "A game model for GSC management based on government subsidies," Journal of Management Science China, vol. 14, no. 6, pp. 86-95, 2011.

[33] Q. X. Li, M. N. Shi, and Y. M. Huang, "A dynamic price game model in a low-carbon, closed-loop supply chain considering return rates and fairness concern behaviors," International Journal of Environmental Research and Public Health, vol. 16, no. 11, pp. 9-26, 2019.

[34] Y. Yan, R. Zhao, and H. Chen, "Prisoner's dilemma on competing retailers' investment in green supply chain management," Journal of Cleaner Production, vol. 184, pp. 65-81, 2018.

[35] P. Zhang, Y. Xiong, Z. Xiong, and W. Yan, "Designing contracts for a closed-loop supply chain under information asymmetry," Operations Research Letters, vol. 42, no. 2, pp. 150-155, 2014. 